\title{
Win-Win-Win: Reflections from a Work-Integrated Learning Project in a Non-Profit Organization
}

\author{
Dale MacKrell \\ University of Canberra, Canberra, ACT, Australia
}

dale.mackrell@canberra.edu.au

\begin{abstract}
This paper reports on the educational aspects of an information systems work-integrated learning (WIL) capstone project for an organization which operates to alleviate homelessness in the Australian non-profit sector. The methodology adopted for the study is Action Design Research (ADR) which draws on action research and design research as a means for framing a project's progress. Reflective insights by the project stakeholders, namely, students, academics, and the non-profit client, reveal a curriculum at work through internal features of the organization; personal features of the participants and features of the external environment. Preliminary findings suggest that students in a WIL project for a non-profit are highly engaged, especially when they become aware of the project's social value. As well, the improvement of professional skills and emotional intelligence by students is more likely in real-life practice settings than in other less authentic WIL activities, equipping graduates for the workforce with both strong disciplinary and generic skills. Win-win-win synergies through project collaboration represent worthwhile outcomes to education, industry and research.
\end{abstract}

Keywords: Work-integrated learning, workplace learning, non-profit, reflection, engagement, IT.

\section{Introduction}

Work-integrated learning, integrating work-based learning into the student experience, is expanding rapidly across all academic disciplines in Australia. As Staehr, Martin, and Chan (2014) explain, this approach is imperative since IT employers are currently more likely to employ workready graduates. As well, there are advantages for the various stakeholders, namely, students, academics, and participating industry partners.

Staehr et al. (2014) assert that reflective practice differentiates work-integrated learning from work experience. Integrating education and research, the project in this paper is industry-oriented, providing a platform for students to enter the workplace and for academics as researchers to de-

Material published as part of this publication, either on-line or in print, is copyrighted by the Informing Science Institute. Permission to make digital or paper copy of part or all of these works for personal or classroom use is granted without fee provided that the copies are not made or distributed for profit or commercial advantage AND that copies 1) bear this notice in full and 2) give the full citation on the first page. It is permissible to abstract these works so long as credit is given. To copy in all other cases or to republish or to post on a server or to redistribute to lists requires specific permission and payment of a fee. Contact Publisher@,InformingScience.org to request redistribution permission. rive guidelines for non-profit organizations in improving their decisionmaking and reporting performance through the adoption of business intelligence solutions. The aim of the paper is to report on the issues of student engagement through participation in a reallife project with strong social and community worth.

The non-profit in the study is Connections $A C T$, a local Canberra organization 
whose main activities are the provision of services in the Australian Capital Territory (ACT) for homeless persons, such as outreach support services and crisis accommodation. Connections ACT focuses on the holistic relationship between people and their chosen families and communities. Non-profits such as Connections $A C T$ are increasingly reliant on accurate and quickly-retrievable organizational data for regulatory reporting and on-going funding. This is difficult to realize for most non-profits since the software available is predominantly suited to organizations in the forprofit sector and their databases are often diverse and non-linking. By addressing Connections $A C T^{\prime}$ 's software challenges, the project in the study is enabling the organization to concentrate its limited resources on core business (helping the homeless) rather than improving IT services.

The intent of the WIL project is to design a data mart and reporting tools in the Cloud to capture, store, and retrieve quality integrated data as first steps towards a business intelligence (BI) solution. The construction of operational BI artefacts takes place progressively in Connections ACT. The aim is to keep costs low and to utilize available resources - student IT project teams and internships, funding from grants, university technical expertise, community support, and smart design options such as open source software and Cloud computing. University of Canberra (UC) student teams, usually comprising a project leader, analyst, developer, and tester, build tailored software artefacts for the non-profit during their final semester of studies as part of a WIL subject offered as a capstone. This project is ongoing, incremental, empirical, and heavily iterative with one to three new student teams each semester allocated to the project until planned implementation and closure in 2016.

The project is incorporated in a WIL subject called IT Project in a Bachelor of Business Informatics (BBI) course. See Appendix A for the curriculum where IT Project is shaded in mauve and Appendix B for the generic skills and graduate attributes expected to be acquired by UC graduates during the period of their studies.

The methodology adopted for the study is Action Design Research (ADR) which draws on action research and design research (Sein, Henfridsson, Purao, Rossi, \& Lindgren, 2011). ADR is a socio-technical approach which takes place through a predefined reflexive process to address a problem-solving situation while stakeholders learn from the intervention. ADR consist of four stages and seven principles as presented in Table 1 in the Research Strategy section.

Stakeholder insights are analyzed in this paper through Moore's analytical lens (2004) which comprises 1) internal features of the organization, 2) features of the external environment, and 3) personal features of the participants, to reveal a curriculum at work. While Moore's framework may seem simplistic, it is appropriate for this context in allowing findings from the data to emerge.

The research problems to provide focus for the study and to be addressed in this paper are 1) whether WIL students are more engaged when working on a project with strong social and community values, and 2) whether synergy amongst the stakeholders, in this case, students, academics and industry partners, from the project can be represented in a model.

The structure of the paper is as follows. A review is provided of the relevant literature on educational aspects related to student work-readiness. This is followed by an outline of the research strategy used, specifically ADR, the research setting, and the analysis section where the data is analyzed using Moore's framework. In the discussion section, the preliminary findings are represented in a Win-Win-Win model (see Figure 2) based on Xia, Caulfield and Ferns (2014) model (see Figure 1). In the concluding section, the findings are related back to the literature. 


\section{Literature Review}

There are competing burdens on the ICT sector from government, industry, and academic sources. The Association of Professional Engineers, Scientists and Managers (APESMA) notes that, over the next decade, the information and technology sector will be marked not only by cyclical skill demands but also by significant systemic supply shortages. The APESMA report (2013, p. 8) claims,

The complexity of aligning skills development with demand and ensuring the tertiary sector is responsive to industry needs in the short and long-term is complicated by the rapid rate of technological change.

It is not surprising that APESMA advocates initiatives which encourage industry collaboration with universities on the skills required to produce work-ready graduates. In the literature review, we discuss various terms associated with attempts to alleviate employability alarms through educational tactics, these being work-integrated learning (WIL), capstones, enquiry-based learning and efforts to boost professionalism in graduates.

\section{Work-Ready with WIL and Capstones}

Work integrated learning (WIL) is about learning through work and work-like experiences thus making students more prepared for the workforce. A definition adopted by the University of Canberra (UC) for the policy document is "work-integrated learning is deliberate and intentional learning in work, supported by appropriate induction of students and supervisors, and imaginatively embedded assessment" (WIL Working Group, 2010). WIL learning activities cover a diverse range of activities from internships and clinical placements to industry and community projects and other practical, contextualized tasks where educationalists attempt to link learning in academic and practice settings. The integration of educational theory with the practice of work within a purposefully designed curriculum is advocated by Patrick, Peach, Pocknee, Webb, Fletcher, and Pretto (2008). From a study of students in workplace settings, Fitch (2011) and Krause (2006) endorse the encapsulation of authentic practice situations and engagement in workplace activities while Jackson (2014) insists that WIL activities complement not replace traditional learning settings.

While WIL may be situated at any stage of a student's degree, a capstone subject is usually taken in a student's final semester or year. As well as providing an opportunity to encapsulate previously acquired knowledge, skills, and experiential learning, it is designed to prepare students for the next stage in their careers, whether in the workplace or in further studies. Capstones can be 'mountaintop' capstones (multi-disciplinary), or 'magnet' (major-specific) or 'mandate', that is, mandated by a regulatory body such as the Australian Computer Society or AACSB or TEQSA (Bailey, van Acker \& Fyffe, 2012). Dunlap (2005), in a study of IT capstones, found students' self-efficacy improved after taking a capstone subject that used an enquiry-based learning (EBL) approach, thus allowing students to apply their university-acquired knowledge and skills in an genuine practice situation.

Enquiry-based learning (EBL) challenges and encourages students for complex situations. EBL has similarities with problem-based learning in that the handling of a problem drives the whole learning experience with curriculum structured by a series of problems. EBL represents a shift from more passive methods of learning to one where students as individuals or teams are actively encouraged to construct their own knowledge, to pursue their own line of enquiry, drawing on existing understandings and identifying learning needs. In this way, students are engaged as partners in the enquiry process as they take responsibility for their learning and support each other by sharing opinions and experiences (Kahn \& O'Rourke, 2005). EBL is related to WIL in that EBL 
principles stress the linking of educational theory with workplace practices to engage students in realistic learning experiences (Xia et al. 2014).

\section{Employability and Professionalism}

All these endeavors, WIL, capstones, and EBL, are recognized means of increasing a graduate's employment prospects. Employability is a major concern for students for whom a good degree leads to a satisfying career. Employability or work-readiness, it is argued, has consequences for university reputations, retention rates and course demands (Orrell, 2004). Graduate employability and employment levels are pivotal interests of higher education institutions which regularly monitor academic achievements and employment rates as part of their quality assurance procedures. These indicators may be crucial to the performance and reputation of educational institutions (Bullock, Gould, Hejmadi \& Lock, 2009).

The notion of graduate employability is multifaceted. It is generally agreed that a combination of skills, 'hard' (frequently referred to as disciplinary or technical skills) and 'soft' (often referred to as generic or non-technical skills), is needed to produce work-ready graduates. While the core notion is to obtain a job, Harvey (2001) emphasizes that employability is often construed as an institutional achievement without taking into account the propensity of students to find employment and the efforts of employers to convert employability into employment. Cranmer (2006) states, despite the best intentions of academics, it is unrealistic to expect universities to guarantee that students will possess both the necessary disciplinary and generic skills on graduation. Xia et al. (2014, p. 3) go further to claim that the responsibility of universities is to be not only knowledge providers for industry partners but also intellectual capital builders through human capital, structural capital and client capital. The collaborative approach of students and academics with industry partners is represented in their model in Figure 1. Whatever the arguments, universities are responding to the challenge by re-appraising graduate professional learning objectives and outcomes with curriculum design and renewal (Litchfield, Nettleton \& Taylor, 2008).

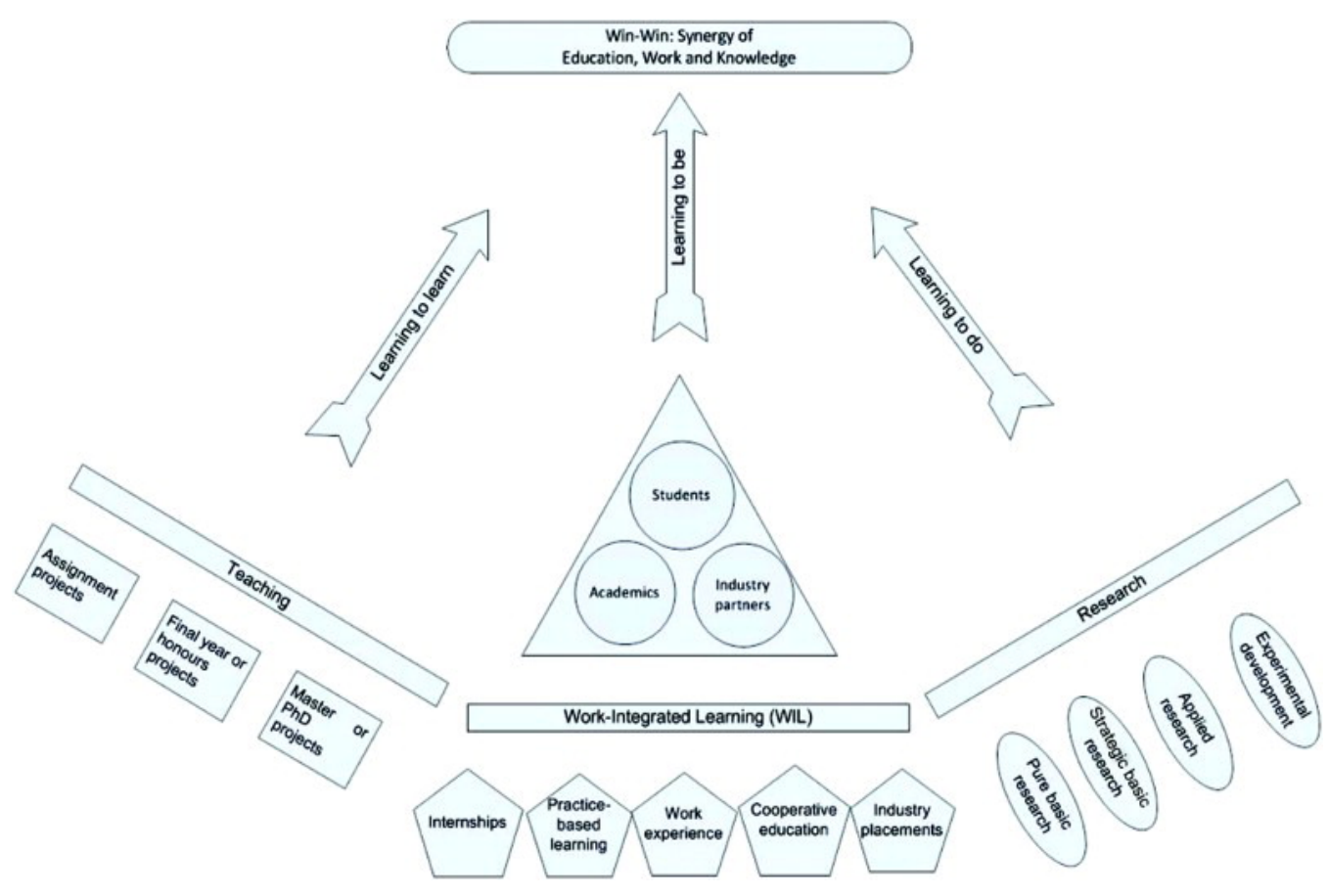

Figure 1: Work-integrated learning framework (Xia et al., 2014) 
In a study aimed to identify and contextualize work-ready skills, Litchfield et al. (2008) developed a comprehension of professionalism. Professionals need to learn how to work in and manage complex situations that encompass uncertainty, instability, uniqueness, and value conflicts. Professional attributes include demonstrating integrity and maturity when dealing with others and, at the highest level, acting in a way that encompasses leadership and emotional intelligence. Three key aspects of professionalism were classified by Wilson, Åkerlind, Walsh, Stevens, Turner, and Shield (2013, p. 1224). Essentially, these are:

1. Exercising specialist knowledge and skills

2. Identifying as a member of a professional community of shared practices and values

3. Having a genuine sense of responsibility and service for your professional community

Wilson et al. (2013) found from their study that students had only a limited awareness of professionalism. Learning activities must therefore prepare students to develop disciplinary and generic skills to work reflectively and ethically in dynamic, complex and ambiguous circumstances (Fitch, 2011, p. 14). According to Jackson (2014), the collaborative responsibilities of educators and employers are to provide students with clear guidance such as goal setting, performance management reviews and reflective practices.

Reflective writing of workplace activities by students is fitting, using tools such as personal journals and presentations (Pavlovich, 2007). Critical reflection is even more desirable to encourage students to recognize strengths and weaknesses of their work, to apply educational theory to workplace practices, and to ascertain future learning needs (Jackson, 2014, p. 3). There has been some discussion in the WIL educational literature as to whether or not reflection for assessments should be structured or more organic (Dean, Sykes, Agostinho, \& Clements, 2012). Students in UC projects and internships seem to welcome reflective journals. This is particularly so when assessments are scaffolded, with presentations and reports building on personal journal entries. Topics are suggested to the students encouraging them to analyze both successes and failures in the workplace, to recognize the links between educational theory and workplace practices, and to discourage students from blindly describing everything through 'rose-colored' glasses with the mistaken intention of pleasing academics and industry partners.

In brief, a review of the literature lends support to addressing employability and professionalism of graduates by improving the alliance between theoretical learning and practical know-how and encouraging critical reflection by students.

\section{Research Strategy}

The methodology of the research project is Action Design Research (ADR), a contemporary socio-technical approach initiated by Sein et al. (2011). ADR draws on action research and design research, valuing both organizational relevance and technological rigor. The ADR approach builds on work by Cole, Purao, Rossi, and Sein (2005) to prescribe four stages, namely, Problem Formulation, Building, Intervention and Evaluation (BIE), Reflection and Learning, and Formalization of Learning within which are seven principles as set out in Table 1.

The stages of ADR are iterative and this project is hovering around the second stage: Building, Intervention and Evaluation (BIE). The project BIE stage is broken down into mini-projects which recur in a cyclical fashion until completed by each student team. BIE relies on evaluations to keep the project on track, and it is these evaluations which have provided important insights into stakeholders' attitudes and the project's vicissitudes (Sein et al., 2011). The evaluations consist of both formal technical audits of software and documentation and less prescribed social appraisals of content, context and process (CCP) by regular stakeholder interviews (MacKrell \& McDonald, 2014). Technical audits occur when student teams are expected to fulfil project documentation requirements, complete a comprehensive testing schedule, and deliver to the industry 
client a functioning artefact, all of which are assessed and graded. These assessments are formal, with a concentration on technical and tangible aspects of system design and development such as modelling specifications.

Table 1. Action Design Research Stages and Principles (Sein et al., 2011)

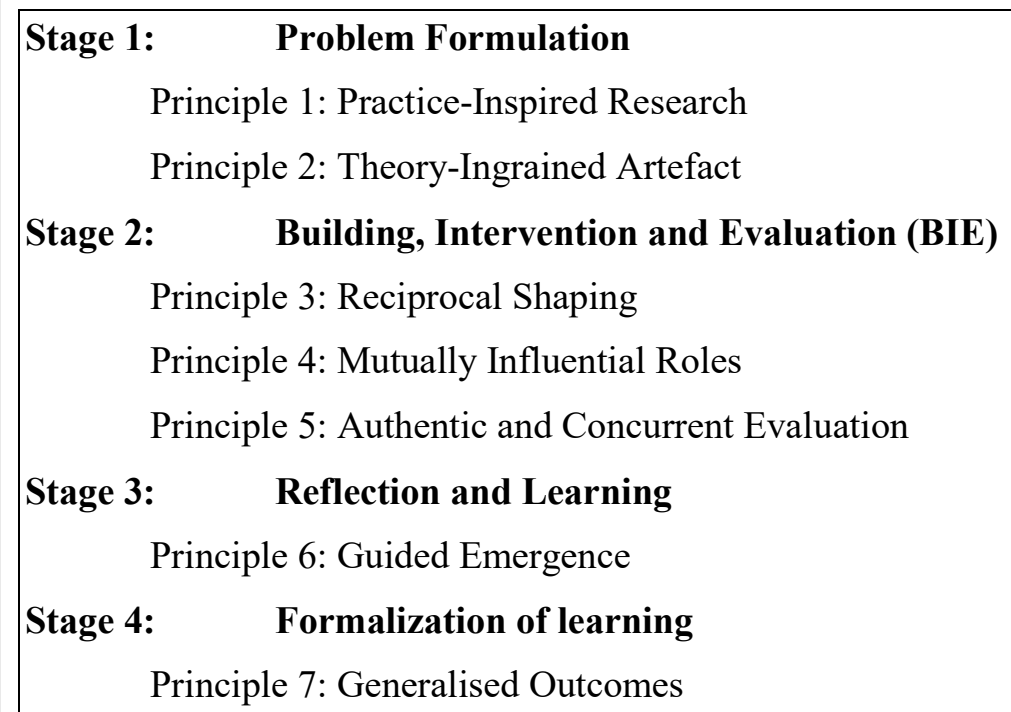

The social dimension is called into play through less formal qualitative evaluations by interviews and e-journals (Koch, 2010). In general, interviews or meetings during the project are face-toface, semi-structured, conversational, and conducted with a single person or the whole student team. During the requirements elicitation phase in 2012, nine interviews were conducted with senior Connections ACT managers and one Board member, as well as three group meetings with University of Canberra BI and data warehouse experts to ascertain the status of technology and information needs in the non-profit. From when the project began in 2013, meetings with Connections ACT managers and staff as the client, and with IT student teams as software developers, have been conducted at several points in the semester: at the start and end of each semester, midsemester and/or any crises point. While interviews and meetings are comparatively informal, they are guided by a prepared interview script or meeting agenda in order to ensure all topics are covered. See Appendix C for an example of an interview script for a meeting with client management.

Most interviews and meetings have been recorded then transcribed, resulting in about 50 hours of interview data to build a comprehensive and longitudinal account of the project. Connections $A C T$ organizational documents and Board papers have provided a complementary triangulated perspective of the project in transition.

\section{Data Analysis: What We Found}

A simple but effective conceptual framework devised by Moore (2004) is employed to analyze the interview and journal data. Moore's (2004) notion that learning in the workplace is socially constructed, with some workplaces being more knowledge rich than others, draws from constructivist theory which accentuate the ways knowledge is created (Bailey et al., 2012). Through Moore's analytical lens, the influences shaping the curriculum in the workplace can be ascertained. The major categories - internal features of an organization, features of the external envi- 
ronment, and personal features of participants - are used in the following analysis. Extracts from interviews and journals are provided to illustrate pertinent points.

\section{Internal Features of the Organization: Organizational Structure, Ideology and Roles}

The organization is the workplace client, Connections $A C T$, committed to helping disadvantaged persons who are homeless (or at risk of becoming so). The vision of Connections ACT is 'people and families connected in their communities'. Connections ACT makes an important contribution to fostering the resilience of communities on the fringes of society and struggling with day-to-day life. Its mission is to deliver quality community services of social value and practical benefit; to support the diversity of sustainable approaches; to foster new evidence-informed approaches that support individuals and families; and to demonstrate excellence in governance, management and service provision (www.connectionsact.org.au).

Homelessness has emerged as an important social and political issue for governments around the world in recent years. The Australian Bureau of Statistics (ABS, 2012) defines homelessness as "when a person does not have suitable accommodation alternatives." Within this context, a person would be homeless if they are living in a dwelling that is inadequate, has no tenure or their initial tenure is short and not extendable, or they do not have control or access to space for social relations. The persistence of the homelessness problem in Canberra, despite significant investments by the Federal and ACT Governments, suggests a possible misalignment between the services provided and the needs of homeless persons. The project has the potential to identify the impact of service programs on the homeless problem.

Connections ACT consists of two services CanFaCS and First Point. The four managers who are involved in the study are the manager of First Point (Jo), the manager of CanFaCS, the Connections ACT Business Manager, and the Acting Executive Officer (EO). While none of these managers have IT backgrounds, they do have technical nous and deep experience of the community sector. Typically the concern of staff is their homeless clients, with IT seen as a less important support tool.

In order to understand the discourse of study participants, an explanation of IT systems in Connections $A C T$ is provided:

- $\quad$ Excel spreadsheets for managing the occupancy and maintenance of properties for Can$\mathrm{FaCS}$. Data related to nine properties and rental bookings are located in various non-structured repositories such as spreadsheets and whiteboards matrices.

- SQL database called SHIP (Specialist Homelessness Information Platform) with a Webbased interface built by a Melbourne-based external consultant for the collection of demographic homeless client data for First Point. It has limited standard and customized reporting features.

- SQL database called Daily Capacity Report (DCR) developed with Alpha 5 technology built for First Point by a Melbourne-based external consultant for tracking accommodation and outreach availability. The system is not supported and has limited reporting features.

- $\quad$ BitCloud is a commercial enterprise for hosting applications in the Cloud at a commercial financial cost to Connections ACT.

The vision of both the project coordinator (an academic as educator, researcher, and project facilitator) and the managers of Connections $A C T$ (as the user and client) was to create a data repository linking disparate databases for management monitoring and regulatory reporting purposes. This is being achieved through mini-projects for each student team, such as, building a database to replace numerous Excel spreadsheets, coding reporting tools for existing software, creating 
Excel macros to speed-up compliance reporting processes for the client, and setting up a development and test environment in the Cloud for the data mart.

The project for Connections ACT could be described as 'top-down with ill-defined goals' (Turner \& Cochrane, 1993) in that neither the goals nor the methods of achieving them were well defined. Turner and Cochrane (1993, p.9 4) state "When the methods are uncertain, the startup process should involve multidisciplinary teams to reach the best solution. When the goals are uncertain, the startup should involve a facilitator to negotiate agreement between the parties involved in the project". This is an apt description of the project.

Students are allocated to new teams at the start of each semester and assigned a mini-project which they are expected to complete by the end of semester. Mini-projects as a 'small wins' approach (Weick, 1984) were encouraged to generate client confidence in the ability of student teams to produce a working solution (MacKrell \& McDonald, 2014). All the same, while some quality assurance is in place through standard learning and teaching practices, a client-accepted functioning product cannot be guaranteed in a student project. The client was aware of this constraint but was committed to the project all the same.

\section{Features of the External Environment: Government Regulations and Market Pressures}

A serious risk to the organization's operations is a lack of systems integration between CanFaCS and First Point. Connections ACT struggles with onerous compliance reporting because of inadequate software, non-linking databases and poor quality data. These technical problems pose a significant threat to the organization's very viability, a fact recognized by client managers.

Business Manager: They [ACT Government] changed some of the reporting requirements ... probably made the reporting even more difficult for Jo [First Point Manager].

First Point Manager (Jo): Then having to have a different set of KPIs under the current funding agreement required that ...

Business Manager: So we've kind of gone back a step now. Now we're really concentrating around enhancing the reporting capacity.

As the project progressed, there was some hesitancy around the marketing of successful IT products and the prospect of social enterprise to reduce reliance on government funding. The Business Manager remarked, "Even if we don't get the SHIP go ahead, enhancing the DCR is a very good step especially if it's a marketable product - thinking social enterprise here."

\section{Personal Features of Participants: Student Teams, Workplace Clients and Educators}

The project involves many stakeholders: workplace clients, student teams, teaching staff, technical experts (university and community), and the project coordinator as an educationalist, researcher and project facilitator. Mutual learning takes place between stakeholders which is multifaceted. To facilitate the investigation into learning outcomes, the socio-technical and pragmatic elements of knowledge in the work environment are analyzed (Moore 2004).

Initial comments of a social nature from students and users (workplace client managers) were informative and positive. Feedback indicated that the students were keen to do the project, behaved professionally and communicated well with the client. Early in the project, one student attended the launch of Dad's Place, as described in a media release (CanFaCS, 2013), 
Dad's Place is a fully equipped house in the north of Canberra where homeless dads can stay a few nights on a regular basis with their kids. Dads who use Dad's Place are provided with full outreach support to address their homelessness and other issues they may need assistance with.

The student who attended the launch was impressed with the commitment of Connections ACT staff and quickly recognized the value of the project. He expressed this in his own words to his team members,

Student 1: Well, it helps in terms of getting the project working in an ethical situation.

At a later time, one of his team members commented:

Student 2: Yeah and I think - I'm pretty happy with the project [Connections ACT] that we got as well because I think we all discovered quite quickly that it had good worth ...

Aside from an appreciation of the project's social and community worth, the teams rapidly acquired the nuances of organizational processes and business systems and were able to offer constructive comments regarding them. The teams also understood that the users were busy people and were courteous in their requests for time and access. Each team appointed one member to liaise with users, and generally adhered to this rule.

Student 3: I think that we took the professionalism side on quite well. When it came to being told that maybe we weren't doing it the right way or to kind of that feeling like maybe Jo wasn't too happy or excited about what we were doing. It was kind of time for us to rethink about what we were doing and make sure we were doing it right. I think we did well in that aspect.

Student 4: You have to have a professional attitude. Just because you'll be coming and working with a bunch of people that you don't know. You have to be willing to work with them from day one to get the most out of the time you have.

Student 5: I think it was a good experience. Definitely in terms of stakeholder management and stuff like that.

These comments by the students are indicative of a growing sense of professionalism alongside emotional intelligence. By emotional intelligence, we mean the ability to perceive, understand and express emotion, and in particular, the ability to regulate emotion to promote intellectual growth (Mayer, Salovey, Caruso, \& Sitarenios, 2001). A means of improving emotional capability and social relations is through overcoming challenges encountered in teamwork. Teamwork is an integral part of enquiry-based learning. It is well documented that IT students should be not only technically competent but also effective in teams (Dunaway, 2013).

Early major hurdles in the project were of a technical nature although related to the social environment. It came to light that some teams were developing their mini-project systems using programming languages learnt at university, for example, building Windows forms using Microsoft $\mathrm{C} \#$ and SQL when Web forms using open source products may have been superior. While this meant less risk for the student teams since they were working within their 'comfort zone', Connections ACT may incur greater cost at a later date should they be locked into commercial products rather than open source such as PHP and MySQL. Open source with software freely available is recommended by some as a solution for avoiding those pitfalls (Klawans, 2006). Another technical obstacle was the design of a data mart and its installation in the Cloud, hindered not only by the limited technical knowledge of the students but also by restricted access to the data from the government database. Students were learning to take these setbacks into their stride and to deal with them innovatively. 
The pragmatic nature of the tasks was recognized by both students and clients. Pragmatic in this sense refers to whether the designated tasks undertaken in WIL projects are central or peripheral to the organization's needs.

First Point Manager (Jo): It's a beautiful case study I think from an overall perspective of doing IT for a community organization.

Connections ACT continues to be appreciative of the generous donation of time and expertise expended by university-based teams to assist them with their IT solutions. Non-profit organizations in the main have limited resources of funding, personnel, and technical expertise. The teams were aware of resource restrictions and were concerned that, after they departed the project, the organization would not be able to maintain their systems. Negotiations are underway about the continuation of the project into the next semester and reducing handover delays to new student teams. The Business Manager, speaking on behalf of the other managers, concluded:

Yeah, look. I suppose the key takeaway for you today is the certainty I'm still quite strongly committed to this project. All of this work fits within the broader scheme of things for us. We need to adapt and change or there won't be a Connections ACT in the future.

Implicit in this comment is the significance of a non-profit's relationship with the university which relates to the win-win situation described by Xia et al. (2014) in Figure 1. In the case of Connections $A C T$, partnership with the University of Canberra is growing their overall capacity through developing knowledge of computing hardware and software systems, capturing and converting this knowledge into business products and services for further application, and enabling the industry partner to pass on the benefit of enhanced capabilities to homeless clients.

\section{Discussion of the Findings}

Identified early are the research problems to be addressed in this paper. These are 1) whether WIL students are more engaged when working on a project with strong social and community values, and 2) and whether synergy from the project amongst the stakeholders, in this case, students, academics and industry partners, can be represented in a model.

The response to the first problem is positive and of practical significance. Studies by Fitch (2011) and Krause (2006) indicate that students are more highly motivated when faced with authentic tasks in realistic settings and that engaged students become more deeply involved in their own learning. This project is distinctive and underpinned by interest in supporting the valuable social and community work of non-profits, like Connections ACT. The students express enthusiasm for the project and this attitude correlates with findings from a paper by Ma, Boland, and Phillips (2010) which examined WIL placements in non-profit organizations. As the project with the nonprofit moves towards completion, it is having transformative affects and showing emergent gains beyond the initial goals of stakeholders, especially attitudinal and educational benefits for all participants. This has the effect of building a more robust community of practice.

According to Jackson (2014) and Pavlovich (2007), critical reflection and evaluation are instrumental in the attainment of a professional attitude. Assessable critical reflective writings in eportfolios by the students and mandatory evaluations though interviews and meetings, conducted within the ADR framework have revealed the improvement of generic traits such as teamwork, critical thinking, social responsibility and an emergent professional attitude. The acquisition of these high-order generic skills, in addition to technical skills, equips students well for future ICT employment and for the assumption of responsibility for their own learning. 


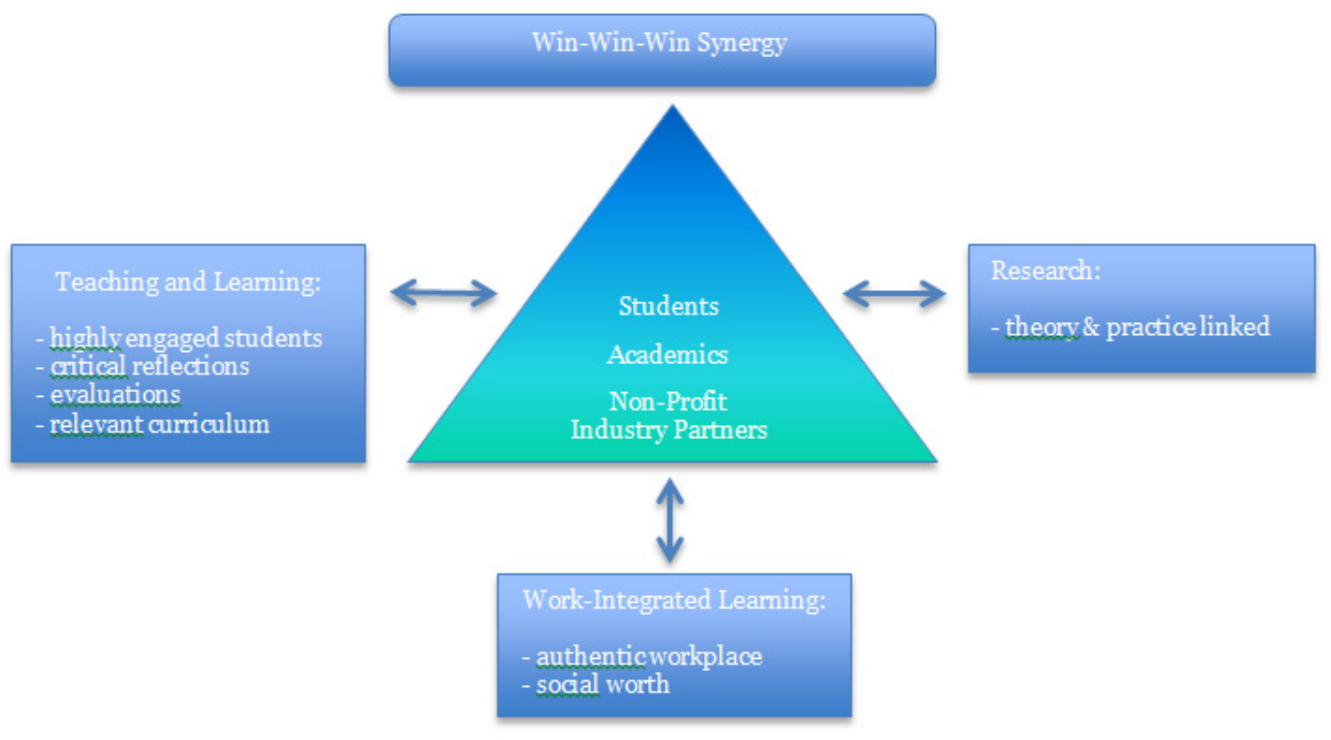

Figure 2: Win-Win-Win Synergy: revised and simplified non-profit work-integrated learning framework (adapted from Xia et al., 2014)

The response to the second problem is illustrated by the Win-Win-Win synergy model in Figure 2, which is an adaptation and simplification of the Xia et al. (2014) model in Figure 1. The model in Figure 1 has much to commend it, especially for linking educational theory with workplace practice when students are engaged in realistic learning experiences as enquiry-based learning (Xia et al. 2014). Yet, the model requires reworking to account for socially constructed influences such as social worth and high student engagement when a non-profit is involved. These influences emerged from the data through the conceptual lens of Moore's (2004) framework. The reworked model is represented in Figure 2 to depict a Win-Win-Win scenario where collaboration takes place with stakeholders in the WIL non-profit project. This model is the theoretical contribution of the paper. A drawback of the study is the single case. It would be worthwhile conducting the study in another organization in the third sector.

\section{Concluding Remarks}

While the project undeniably has its setbacks and limitations, overall benefits are evident for all stakeholders: students are engaged, learning through authentic work placements and participating in reflective practices, resulting in being more work-ready; staff of the industry non-profit are benefitting from shifts in attitude towards greater understanding of their own systems and their association with the university sector; while academics as educators and researchers are utilizing feedback from student reflections for generating new knowledge and are re-examining the curriculum with a view to being more relevant. This outcome is consistent with the multi-prong approach promulgated by Staehr et al. (2014) such that all participants can benefit from workintegrated learning. 


\section{References}

Australian Bureau of Statistics (ABS). (2012). Information paper - A statistical definition of homelessness: Domestic and family violence. Retrieved November 20, 2104 from http://www.abs.gov.au/AUSSTATS/abs@.nsf/Latestproducts/4922.0Main\%20Features72012?opendoc ument\&tabname $=$ Summary \&prodno $=4922.0 \&$ issue $=2012 \&$ num $=\& v i e w=$

Association of Professional Engineers, Scientists and Managers, Australia (APESMA). (2013). Addressing ICT workforce challenges. Retrieved September 1, 2014 from http://www.professionalsaustralia.org.au/groups/information-technology/APESMA-Submission-toAWPA---Addressing-ICT-workforce-challenges.pdf

Bailey, J., van Acker, E., \& Fyffe, J. (2012). Capstone subjects in undergraduate business degrees: A good practice guide. Griffith University, Brisbane Australia.

Bullock, K., Gould, V., Hejmadi, M., \& Lock, G. (2009). Work placement experience: Should I stay or should I go ? Higher Education Research \& Development, 28(5), 481-494.

CanFaCS. (2013). Dad's Place media release. Retrieved November 3, 2015 from http://www.canfacs.org.au/dads-place-making-a-difference-to-the-lives-of-local-fathers-and-theirfamilies/

Cole, R., Purao, S., Rossi, M., \& Sein, M. (2005). Being proactive: Where action research meets design research. Proceedings of the $26^{\text {th }}$ International Conference on Information Systems (ICIS), Las Vegas USA.

Cranmer, S. (2006). Enhancing graduate employability: Best intentions and mixed outcomes. Studies in Higher Education, 31(2), 169-184.

Dean, B., Sykes, C., Agostinho, S., \& Clements, M. (2012). Reflective assessment in work-integrated learning: To structure or not to structure, that was our question. Asia-Pacific Journal of Co-operative Education, 13(2), 103-113.

Dunaway, M. (2013). IS learning: The impact of gender and team emotional intelligence. Journal of Information Systems Education, 24(3), 189-202.

Dunlap, J. (2005). Changes in students' use of lifelong learning skills during a problem-based learning project. Performance Improvement Quarterly, 18(1), 5-33.

Fitch, K. (2011). Developing professionals: Student experiences of a real-client project. Higher Education Research \& Development, 30(4), 491-503.

Harvey, L. (2001). Defining and measuring employability. Quality in Higher Education. 7(2), 97-109.

Jackson, D. (2014). Employability skill development in work-integrated learning: Barriers and best practice. Studies in Higher Education. DOI: 10.1080/03075079.2013.842221

Kahn, P. \& O'Rourke, K. (2005). Understanding enquiry-based learning. In T. Barrett, I. Mac Labhrainn, \& H. Fallon (Eds), Handbook of Enquiry \& Problem Based Learning, TCELT Galway.

Klawans, B. (2006). Saving time and money - Why open-source BI makes sense. Business Intelligence Journal, 11(4), 18-24.

Koch, A. (2010). The e-Portfolio as an enabler for work-integrated learning in universities of technology. Proceedings of the Informing Science and Information Technology Education Conference, Montecassino, Southern Italy, June 2010.

Krause, K. (2006). Quality issues in ICT-based higher education. Studies in Higher Education. 31(6).

Litchfield, A., Nettleton, S., \& Taylor, T. (2008). Integrating work-ready learning into the university curriculum contextualised by profession. Proceedings of the Conference for Work-Integrated Learning: Transforming Futures, Sydney Australia. 
Ma, W. Boland, G., \& Phillips, D. (2010). A study on exploring the expansion of IT WIL programs into non-IT organisations. Proceedings of the Australian Collaborative Education Network National (ACEN) Conference, Perth Australia.

MacKrell, D. \& McDonald, C. (2014). Incorporating content, context and process evaluation into action design research. Information Systems Foundation Workshop. The National Centre for Information Systems Research ANU. https://www.rsabis.anu.edu.au/research-centres/ncisr/isf-2014-workshop September 2014.

Mayer, J., Salovey, P., Caruso, D., \& Sitarenios, G. (2001). Emotional intelligence as a standard intelligence. Emotion, 1(3), 232-242. http://dx.doi.org/10.1037/1528-3542.1.3.232

Moore, D. T. (2004). Curriculum at work: An educational perspective on the workplace as a learning environment. The Journal of Workplace Learning, 16(6), 325-340.

Orrell, J. (2004). Work-integrated learning programmes: Management and educational quality. Paper presented at the Australian Universities Quality Forum, Adelaide Australia.

Patrick, C-J., Peach, D., Pocknee, C., Webb, F., Fletcher, M., \& Pretto, G. (2008). The WIL (Work Integrated Learning) report: A national scoping study (Australian Learning and Teaching Council ALTC Final Report). QUT Brisbane. Available online at: www.altc.edu.au and www.acen.edu.au .

Pavlovich. K. (2007). The development of reflective practice through student journals. Higher Education Research \& Development, 26(3), 281-295.

Sein, M., Henfridsson, O., Purao, S., Rossi, M., \& Lindgren, R. (2011). Action design research, MIS Quarterly, 35(1), 35-56.

Staehr, L., Martin, M., \& Chan, K. (2014). A multi-pronged approach to work integrated learning for ITstudents. Journal of Information Technology Education: Innovations in Practice, 13, 1-11. Retrieved November 7, 2015 from http://www.jite.org/documents/Vol13/JITEv13IIPp001-011Staehr0454.pdf

Turner, J. \& Cochrane, R. (1993). Goals-and-methods matrix: Coping with projects with ill-defined goals and/or methods of achieving them. International Journal of Project Management, 11(2), 93-102.

Weick, K. (1984). Small wins: Redefining the scale of social problems. American Psychologist, 39(1), 4049.

WIL Working Group. (2010). What is Work-Integrated Learning ?.Work Integrated Learning Policy, University of Canberra. Retrieved September 1, 2014 from http://www.canberra.edu.au/futurestudents/work-integrated-learning

Wilson, A., Åkerlind, G., Walsh, B., Stevens, B., Turner B. \& Shield, A. (2013). Making 'professionalism' meaningful to students in higher education. Studies in Higher Education, 38(8).

Xia, J., Caulfield, C., \& Ferns, S. (2014). Work-integrated learning: Linking research and teaching for a win-win situation. Studies in Higher Education, DOI: 10.1080/03075079.2014.882302 


\section{Appendix A: Disciplinary Subjects in Curriculum}

\section{Bachelor of Business Informatics - Standard FT S1 Commencing (2016)}

\begin{tabular}{|l|l|}
\hline Semester $\mathbf{1}$ & Semester $\mathbf{2}$ \\
\hline Year $\mathbf{1}$ & \\
\hline 6348 Information Systems in Organisation & 9515 Database Design \\
\hline 4207 Introduction to Management & 7878 Organisational Behaviour \\
\hline 5123 Business Statistics & 7722 Professional Practice in IT \\
\hline 9799 Foundations of Professional Planning & 5617 Accounting for Managers \\
\hline Year $\mathbf{2}$ & \\
\hline 6389 Designing Human-Computer Interaction & 7034 Information Law \\
\hline 7079 Organisational Performance & 7087 Sociology of Technology and Work \\
\hline Open Elective & 6365 Systems Analysis and Modelling \\
\hline Open Elective & Open Elective \\
\hline Year 3 & \\
\hline 7156 Business Intelligence Systems & 7155 Business Informatics Case Studies \\
\hline 6388 Document and Workflow Management & 7164 Information Technology Project (6cp) \\
\hline 7173 Systems Project and Quality Management & Restricted Choice (2) \\
\hline Restricted choice (1) & \\
\hline
\end{tabular}

(Source: University of Canberra. (2015). Comprehensive Course Review for 2016 and Onwards, http://www.canberra.edu.au/coursesandunits/course?course cd=706AA\&version number $=4$ \&location cd=BRUCE, retrieved May 2016)

\section{Appendix B: University of Canberra Graduate Attributes}

UC graduates are work-ready. They possess the knowledge, skills and attitudes needed to succeed in their profession and more broadly, across a wide range of professional contexts.

1. UC graduates are professional. Because we collaborate closely with industry and other stakeholders, our graduates have the knowledge, skills and attitudes to succeed in their profession and become leaders in their field.

2. UC graduates are global citizens. We support students to gain the knowledge and confidence to be global citizens.

3. UC graduates are lifelong learners. Our graduates are passionate about being at the forefront of their profession, staying in touch with the latest research, news and technology.

(Source: University of Canberra. (2016). Attributes of UC graduates (coursework students) Poli$c y$, https://guard.canberra.edu.au/policy/policy.php?pol id=3344, retrieved May 2016) 


\section{Appendix C: Interview Script for Connections ACT Managers}

1. Did we prepare you adequately for the student team ?

2. How was the handover from the previous team ?

3. Was the student team adequately prepared with reference to technical skills, business knowledge, generic skills, emotional intelligence, and professional attitude ?

4. Do you think the team followed the right process eg request meetings with users ahead of time?

5. Did the team have too little/too much contact with you ?

6. Did the team implement a useful and working product ?

7. How can the product be improved ?

8. If another team came to your workplace, what can they achieve to extend the work of the previous team?

9. High and low points of the semester?

10. Any additional comments ?

\section{Biography}

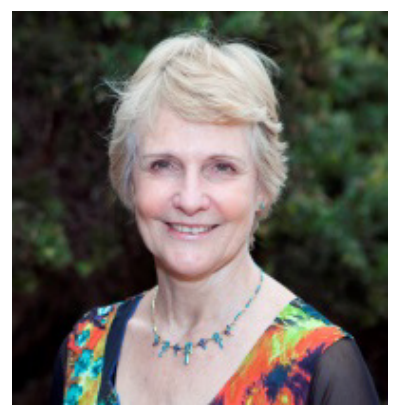

Dale MacKrell has a track record of professional contributions as a researcher and educator in the Information Systems discipline. Her scholarly interests include business intelligence and gender relations in the rural sector, and a cooperative learning project for a not-for-profit organization operating in homelessness. Dale has published in the Information Systems Journal, Decision Support Systems journal and the Australasian Journal of Information Systems as well as numerous Australian and international conferences. Dale is an Assistant Professor in Information Systems at the University of Canberra in Australia. 